OPEN ACCESS

Edited by:

Jared Brent Smith,

Regenxbio Inc., United States

Reviewed by:

Jones Parker,

Northwestern University,

United States

Vincent Laurent,

University of New South Wales,

Australia

Nick Garber Hollon,

Salk Institute for Biological Studies,

United States

*Correspondence:

Alban de Kerchove d'Exaerde alban.de.kerchove@ulb.be

Received: 18 May 2021

Accepted: 22 June 2021

Published: 15 July 2021

Citation:

De Groote $A$ and

de Kerchove d'Exaerde A (2021)

Thalamo-Nucleus Accumbens

Projections in Motivated Behaviors

and Addiction.

Front. Syst. Neurosci. 15:711350.

doi: 10.3389/fnsys.2021.711350

\section{Thalamo-Nucleus Accumbens Projections in Motivated Behaviors and Addiction}

\author{
Aurélie De Groote and Alban de Kerchove d'Exaerde* \\ Laboratory of Neurophysiology, ULB Neuroscience Institute, Université Libre de Bruxelles (ULB), Brussels, Belgium
}

The ventral striatum, also called nucleus accumbens (NAc), has long been known to integrate information from cortical, thalamic, midbrain and limbic nuclei to mediate goal-directed behaviors. Until recently thalamic afferents have been overlooked when studying the functions and connectivity of the NAc. However, findings from recent studies have shed light on the importance and roles of precise Thalamus to NAc connections in motivated behaviors and in addiction. In this review, we summarize studies using techniques such as chemo- and optogenetics, electrophysiology and in vivo calcium imaging to elucidate the complex functioning of the thalamo-NAc afferents, with a particular highlight on the projections from the Paraventricular Thalamus (PVT) to the NAc. We will focus on the recent advances in the understanding of the roles of these neuronal connections in motivated behaviors, with a special emphasis on their implications in addiction, from cue-reward association to the mechanisms driving relapse.

Keywords: thalamus, nucleus accumbens, goal-directed, reward, addiction

\section{INTRODUCTION}

The nucleus accumbens (NAc), a key node of the reward brain circuitry, is known to be involved in several motivated behaviors and is notably responsible for translating motivation into action in goal-directed behaviors (Mogenson et al., 1980; Ikemoto and Panksepp, 1999; Carelli, 2002; Klawonn and Malenka, 2018; Yang et al., 2018). The NAc is also part of the circuits that support drug addiction (Belin and Everitt, 2008; Yager et al., 2015; Everitt and Robbins, 2016; Scofield et al., 2016), a chronic and relapsing disorder characterized by the continuation of drug use despite harmful consequences (Leshner, 1997; Goodman, 2008). Drugs of abuse hijack normal adaptive changes in the brain that occur in a non-pathological context to drive reward-related learning and memory, thereby involving the NAc (Nestler, 2013).

The NAc receives glutamatergic projections from cortical and thalamic areas in similar abundance (Phillipson and Griffiths, 1985; Doig et al., 2010). These projections innervate the main

\footnotetext{
Abbreviations: AMPA, $\alpha$-amino-3-hydroxy-5-methyl-4-isoxazolepropionic acid; AMPAR, AMPA receptor; aPVT, anterior paraventricular thalamus; $\mathrm{CPA}$, conditioned place aversion; $\mathrm{CPP}$, conditioned place preference; $\mathrm{CRF}$, corticotrophin-releasing factor; D1, dopamine receptor $\mathrm{D}_{1}$; $\mathrm{D} 2$, dopamine receptor $\mathrm{D}_{2}$; GABA, $\gamma$-aminobutyric acid; $\mathrm{MSN}$, medium spiny neuron; MTN, midline thalamic nuclei; NAc, nucleus accumbens; NMDA, $N$-methyl-D-aspartate; NMDAR, NMDA receptor; PFC, prefrontal cortex; pPVT, posterior paraventricular thalamus; PVT, paraventricular thalamus; $\mathrm{PVT}=>$ NAc, paraventricular thalamus neurons projecting to nucleus accumbens; RTPP, real-time place preference; SPN, striatal projection neuron; VTA, ventral tegmental area.
} 
neuronal populations of the striatum, the D1- and D2-Medium Spiny Neurons (MSNs) as well as interneurons (Smith et al., 2004; Doig et al., 2010; Wall et al., 2013; Klug et al., 2018; Johansson and Silberberg, 2020). Although thalamic afferents of the NAc have long been overlooked, recent studies have untangled their functional importance.

The thalamus is composed of the principal (or "relay") sensorimotor nuclei, the "association" nuclei, and the midline and intralaminar thalamic nuclei (Groenewegen and Witter, 2004; Vertes et al., 2015). Thalamic projections to the NAc are mainly concentrated in this last group, and more precisely in the paraventricular thalamic nucleus (PVT) and in the central medial nucleus (Su and Bentivoglio, 1990; Vertes and Hoover, 2008; Vertes et al., 2015). Given the growing evidences highlighting its key role in various motivated behaviors, the PVT is the main focus of this mini-review. Importantly, the PVT is a critical hub for homeostatic and internal state information, and is likely to convey this information to the NAc to influence goal-directed responses to homeostatic challenges (Penzo and Gao, 2021).

The PVT is subdivided into two parts which differ in terms of inputs ( $\mathrm{Li}$ and Kirouac, 2012), outputs, and cellular composition (Gao et al., 2020). The anterior PVT (aPVT) innervates preferentially the dorsomedial NAc shell, while the posterior PVT (pPVT) sends projections mainly to the ventromedial NAc shell (Dong et al., 2017). PVT neurons projecting to the NAc core are less numerous than to the NAc shell, but can be found throughout the anterior-posterior extent of the PVT (Dong et al., 2017). Importantly, PVT connections are highly conserved across species, even though the strength of connections may differ in specific structures (Hsu et al., 2014). However, the distinction between the aPVT and pPVT in human is difficult to identify (Hsu et al., 2014).

Notably, the PVT also stimulates the release of dopamine in the NAc by making close contact with dopamine terminals (Pinto et al., 2003; Parsons et al., 2007; Kirouac, 2015; Perez and Lodge, 2018). Other mechanisms of thalamic-dependent dopamine release cannot be excluded, since the thalamus is able to activate striatal cholinergic interneurons to drive local dopamine release (Threlfell et al., 2012; Kosillo et al., 2016; Johnson et al., 2017; Cover et al., 2019).

\section{THALAMO-NUCLEUS ACCUMBENS PROJECTIONS: REWARDING OR AVERSIVE?}

Given the important role of the NAc in motivated behaviors and the relevance of the PVT in negative emotional behaviors (Hsu et al., 2014; Kirouac, 2021), several groups have tried to assess the motivational valence of the PVT-NAc pathway $(\mathrm{PVT}=>$ NAc) (Table 1). In a real-time place preference assay (RTPP), mice seemed to reduce the time spent in the chamber associated with the optogenetic stimulation of PVT $=>$ NAc shell (Zhu et al., 2016; Do-Monte et al., 2017). This aversion seemed to be dependent on glutamatergic transmission in the NAc, since the avoidance of the optogenetic stimulation was abolished by AMPA receptor (AMPAR) antagonist in the NAc, but not by D1 or D2 antagonists (Zhu et al., 2016). Another paper, however, showed no preference or avoidance of the optogenetic stimulation chamber, highlighting instead the high variability of behaviors during this RTPP (Lafferty et al., 2020). Indeed, some mice avoided the stimulation zone, others increased the time spent in that zone, and a third group had no preference or aversion but a high transition rate between both zones. Interestingly, in an operant chamber, acute PVT $=>$ NAc stimulation contingent to lever press induced self-stimulation, suggesting that brief synchronous activation of these projections is reinforcing rather than aversive (Lafferty et al., 2020). Finally, a recent study showed that the precise stimulation of aPVT neurons expressing corticotrophin-releasing factor (aPVT ${ }^{\mathrm{CRF}}$ ) and projecting to the NAc shell induced behavioral aversion in the RTPP (Engelke et al., 2021).

Overall, the neuronal activity pattern in the PVT seems critical in determining the rewarding or aversive properties of this pathway: brief optogenetic stimulations being possibly reinforcing and prolonged stimulations aversive. Moreover, even though all the studies presented here focused on the $\mathrm{PVT}=>$ NAc shell, the precise shell subregions targeted could explain the discrepancies in the results. Indeed, NAc subregions differentially modulate motivational valence, highlighting distinct functions of the circuits along the mediolateral axis of the shell (Yang et al., 2018), its dorso-ventral axis (De Jong et al., 2019; Yuan et al., 2019) as well as its rostro-caudal axis (Reynolds and Berridge, 2002).

Finally, if the mixed effects of PVT $=>$ NAc stimulation on motivational valence contrast with the rewarding effects of other glutamatergic inputs to the NAc (Stuber et al., 2011; Britt et al., 2012), they however seem to share interesting commonalities with glutamatergic inputs stimulation from the ventral tegmental area (VTA) (Qi et al., 2016; Yoo et al., 2016; Zell et al., 2020). Indeed, brief stimulation of VTA glutamatergic neurons induces positive reinforcement, in opposition to a more sustained stimulation which elicits apparent behavioral avoidance (Yoo et al., 2016).

\section{REWARD-SEEKING BEHAVIORS}

In addition to being an essential relay in wakefulness through a lateral hypothalamus $=>$ PVT $=>$ NAc circuit, (Ren et al., 2018), the PVT also integrates other homeostatic information to influence reward seeking behaviors, including reward consumption and feeding behaviors. A population of PVT glutamatergic neurons expressing the glucose transporter Glut2 (Slc2a2) and projecting to the NAc has been identified. These neurons, controlled by glucose metabolism, are activated by hypoglycemia conditions and mediate sucrose-seeking (Labouèbe et al., 2016). A recent study also revealed the role of aPVT $=>$ NAc in promoting high fat intake, and shed light on the potentiation of aPVT synapses with NAc D1-MSNs after repeated exposure to the high fat reward (Christoffel et al., 2021). Interestingly, aPVT $=>$ NAc seemed to regulate the incentive motivational value of the diet rather than hunger itself, since inhibition of this circuit decreased the preference for a high fat 


\begin{tabular}{|c|c|c|c|c|c|}
\hline & References & Projections & Behaviors & Methods & Results \\
\hline \multirow{23}{*}{$\begin{array}{l}\text { Homeostatic and } \\
\text { reward-seeking } \\
\text { behaviors }\end{array}$} & $\begin{array}{l}\text { Labouèbe et al., } \\
2016\end{array}$ & $\mathrm{PVT}(\mathrm{S} / \mathrm{c} 2 \mathrm{a} 2)=>\mathrm{NAc}$ & Sucrose-seeking & Optogenetic stimulation (terminals) & $\uparrow$ Motivated sucrose seeking \\
\hline & $\begin{array}{l}\text { Do-Monte et al., } \\
2017\end{array}$ & $\begin{array}{l}\text { aPVT }=>\text { NAc (mainly } \\
\text { shell) }\end{array}$ & Sucrose-seeking & Optogenetic inhibition (terminals) & $\uparrow$ Sucrose-seeking during reward omission \\
\hline & & & & Optogenetic stimulation (terminals) & $\downarrow$ Sucrose-seeking \\
\hline & & & RTPP & Optogenetic stimulation (terminals) & Behavioral aversion \\
\hline & Cheng et al., 2018 & $\mathrm{aPVT}=>\mathrm{NAc}$ & Novelty-suppressed feeding task & Optogenetic stimulation (terminals) & $\uparrow$ Feeding \\
\hline & Ren et al., 2018 & $\mathrm{PVT}=>\mathrm{NAc}$ & Sleep & Optogenetic stimulation (terminals) & $\uparrow$ Transitions from sleep to wakefulness \\
\hline & & & & Chemogenetic inhibition (cell bodies) & $\downarrow$ Wakefulness \\
\hline & Meffre et al., 2019 & $\mathrm{pPVT}=>$ NAc core & Sucrose-seeking & Optogenetic stimulation (terminals) & $\begin{array}{l}\uparrow N A c \text { core neuronal responses to } \\
\text { reward-predictive cues in sated animals }\end{array}$ \\
\hline & Otis et al., 2019 & $P V T=>N A c$ & Pavlovian conditioning & $\begin{array}{l}\text { In vivo two-photon calcium imaging of PVT } \\
\text { neurons projecting to the NAc }\end{array}$ & Inhibitory responses to reward-predictive cues. \\
\hline & Lafferty et al., 2020 & $\mathrm{PVT}=>\mathrm{NAc}$ shell & $\begin{array}{l}\text { Operant task with cued periods of } \\
\text { reward unavailability }\end{array}$ & $\begin{array}{l}\text { Optogenetic inhibition (cell bodies or } \\
\text { terminals) }\end{array}$ & $\uparrow$ Unproductive reward seeking \\
\hline & & & $\begin{array}{l}\text { Operant task without periods of } \\
\text { reward unavailability }\end{array}$ & Chemogenetic activation (cell bodies) & $\downarrow$ Reward-seeking \\
\hline & & & RTPP & Optogenetic stimulation (terminals) & High variability \\
\hline & & & Self-stimulation & Optogenetic stimulation (terminals) & Reinforcing \\
\hline & $\begin{array}{l}\text { Christoffel et al., } \\
2021\end{array}$ & $\mathrm{aPVT}=>\mathrm{NAc}$ & Limited-access high fat exposure & Optogenetic stimulation (terminals) & $\uparrow$ High fat intake during acquisition period \\
\hline & & & & Optogenetic inhibition (terminals) & $\begin{array}{l}\downarrow \text { High fat intake during acquisition and } \\
\text { expression periods }\end{array}$ \\
\hline & & & & Chemogenetic inhibition (cell bodies) & $\downarrow$ High fat intake during expression period \\
\hline & & & & $\begin{array}{l}\text { Optogenetic stimulation and brain slice } \\
\text { electrophysiology }\end{array}$ & $\begin{array}{l}\uparrow \text { AMPAR/NMDAR ratio at aPVT }=>\text { D1R-MSNs } \\
\text { synapses }\end{array}$ \\
\hline & & & & Optical LTD induction protocol in vivo & $\downarrow$ High fat intake after optical LTD \\
\hline & & & High fat CPP & Optogenetic inhibition (terminals) & $\downarrow$ High fat paired chamber preference \\
\hline & & & $\begin{array}{l}\text { Operant task: progressive ratio (high } \\
\text { fat pellets) }\end{array}$ & Chemogenetic inhibition (cell bodies) & $\downarrow$ Breakpoint \\
\hline & Engelke et al., 2021 & $\mathrm{aPVT}=>\mathrm{NAc}$ & Conflict test (food and predator odor) & Chemogenetic inhibition (cell bodies) & $\downarrow$ Defensive responses $\uparrow$ Food-seeking behavior \\
\hline & & $\mathrm{aPVT} C \mathrm{CRF}=>\mathrm{NAc}$ shell & Conflict test (food and predator odor) & Optogenetic stimulation (terminals) & $\downarrow$ Food-seeking \\
\hline & & & RTPP & Optogenetic stimulation (terminals) & Behavioral aversion \\
\hline \multirow[t]{5}{*}{$\begin{array}{l}\text { Drug experience } \\
\text { and addiction }\end{array}$} & $\begin{array}{l}\text { Joffe and Grueter., } \\
2016\end{array}$ & $\begin{array}{l}\text { Midline thalamic } \\
\text { nuclei }=>\text { NAc core }\end{array}$ & $\begin{array}{l}\text { Cocaine exposure followed by } \\
2 \text { weeks of abstinence }\end{array}$ & $\begin{array}{l}\text { Optogenetic stimulation and brain slice } \\
\text { electrophysiology }\end{array}$ & $\begin{array}{l}\uparrow \text { AMPAR and NMDAR function at D1R-MSNs } \uparrow \\
\text { Silent synapses at D2R-MSNs }\end{array}$ \\
\hline & $\begin{array}{l}\text { Neumann et al., } \\
2016\end{array}$ & $P V T=>N A c$ shell & Cocaine self-administration & $\begin{array}{l}\text { Disruption of synaptic transmission (tetanus } \\
\text { toxin) }\end{array}$ & $\downarrow$ Acquisition of cocaine self-administration \\
\hline & & & $\begin{array}{l}1-2 \text { days of withdrawal after cocaine } \\
\text { self-admin. }\end{array}$ & $\begin{array}{l}\text { Optogenetic stimulation and brain slice } \\
\text { electrophysiology }\end{array}$ & $\begin{array}{l}\uparrow \text { Silent synapses } \uparrow \text { Presynaptic release } \\
\text { probability }\end{array}$ \\
\hline & & & $\begin{array}{l}45 \text { days of withdrawal after cocaine } \\
\text { self-admin. }\end{array}$ & & $\uparrow$ Presynaptic release probability \\
\hline & Zhu et al., 2016 & $\mathrm{PVT}=>$ NAc medial shell & RTPP & Optogenetic stimulation (terminals) & Behavioral aversion \\
\hline
\end{tabular}


paired chamber, as well as the breakpoint in a progressive ratio task (Christoffel et al., 2021).

Several lines of evidence also suggest a key role of PVT circuitry in adaptive behavior, by influencing the decision to seek or avoid a reward (McGinty and Otis, 2020). A study showed that during behavioral competition between reward and danger, PVT inhibition induced a bias in the behavior, depending on the experimental conditions, toward either reward or defense (Choi and McNally, 2017; Choi et al., 2019), confirming the dual role of PVT $=>$ NAc in aversion and reward. Another study showed that the activation of aPVT $=>$ NAc neurons increased feeding behavior in a novel environment, without altering anxiety behaviors (Cheng et al., 2018). Recently, $\mathrm{aPVT}^{\mathrm{CRF}}=>$ NAc has also been shown to control the conflict between approach-food and avoid-predator threat by suppressing food-seeking in the presence of a predator odor (Engelke et al., 2021). It is likely that the $\mathrm{PVT}=>\mathrm{NAc}$ modulation during conflict also strongly depends on the internal state of the animal as well as on the precise experimental conditions, possibly explaining (in addition to the precise cellular identity of the neurons targeted in the aPVT) the discrepancies between these last two studies.

All these studies seem to indicate a crucial role of $\mathrm{PVT}=>$ NAc in coordinating relevant homeostatic inputs, including arousal and hunger information, to drive contextdependent reward-seeking behaviors (Table 1). Notably, the PVT is extensively innervated by hypothalamic peptides, such as orexin (Kelley et al., 2005; Kirouac et al., 2005), the neuropeptide $\mathrm{Y}$ and cocaine- and amphetamine-regulated transcript, that are likely to contribute to the integration of arousal, feeding, and reward seeking behaviors (Adamantidis and de Lecea, 2009; Choi et al., 2012; Mahler et al., 2014; Sakurai, 2014; Baimel et al., 2015; Lee et al., 2015). Finally, direct connections of hypothalamic orexin neurons with the VTA and the NAc may also play a role in these behaviors, and have been reviewed elsewhere (Haghparast et al., 2017).

Cue-reward association and salience processing are important components of reward seeking behaviors. PVT neurons are activated in response to cues associated with food reward (Choi et al., 2010; Igelstrom et al., 2010), and influence the attribution of incentive values to reward cues (Haight et al., 2015, 2017, 2020; Campus et al., 2019). Moreover, both the midline thalamic nuclei (MTN) and the NAc receive prefrontal cortex (PFC) inputs that are able to modulate conditioned reward seeking through divergent cue encoding in PFC neurons (Otis et al., 2017). Fiber photometry experiments were performed to characterize associative learning in the PVT, and showed that PVT neurons are activated by reinforcing stimuli and predictive cues (Zhu et al., 2018). The PVT responded to cues and stimuli regardless of palatable or aversive outcome, but the intensity of their response reflected the magnitude of the reward or punishment. In addition, PVT responses were modulated by behavioral homeostatic states and were associated with the salience of sensory stimuli in a context-dependent manner. Optogenetic inhibition also demonstrated that PVT responses during the predictive cue and/or the reinforcing stimulus were necessary for reward seeking, aversive learning and extinction (Zhu et al., 2018). Another study also confirmed the involvement of PVT 
neurons in different aspects of cue-induced motivated behavior (Munkhzaya et al., 2020). Finally, PVT neurons also encode reward omission (Do-Monte et al., 2017; Zhu et al., 2018). All these studies highlight the key roles played by thalamic neurons in salience processing (Zhou et al., 2021).

Several groups studied specifically the involvement of PVT $=>$ NAc in cue-reward association and reward-seeking (Table 1). In a cue-induced sucrose-seeking task, omission of the reward during cue-on periods usually leads to an increased reward-seeking response. Photoinhibition of aPVT $=>$ NAc resulted in an even further increase in the reward-seeking during the periods of reward omission, while optogenetic activation of aPVT $=>$ NAc decreased the cue-induced pressing for sucrose (Do-Monte et al., 2017). In a similar study, photoinhibition of PVT $=>$ NAc increased unproductive reward seeking during reward unavailability periods, while pharmacological activation of $\mathrm{PVT}=>$ NAc decreased operant responding during a task in which reward was always available (Lafferty et al., 2020). Both studies highlighted the implications of PVT $=>$ NAc in adapting the reward seeking behavior to the context and reward availability.

To better understand how reward-seeking relevant inputs are integrated by $\mathrm{PVT}=>$ NAc neurons, mice were trained to associate a conditioned stimulus with a sucrose reward (Otis et al., 2019). Calcium imaging revealed that more than half of tracked PVT $=>$ NAc neurons developed an inhibitory response to the conditioned stimulus across learning (Otis et al., 2019). However, electrophysiological recordings demonstrated that both NAc core and pPVT neurons were excited by reward-predictive cues (Meffre et al., 2019). This discrepancy could result from the different population of PVT neurons, or from the precise NAc regions targeted, the NAc shell and core being especially implicated in feeding behavior and incentive-cue responding, respectively (Stratford and Kelley, 1999; Ambroggi et al., 2011). Interestingly, the hunger state of the animal modulated these neuronal responses in the NAc core and PPVT, and orexin transmission in the pPVT increased sucrose-seeking and NAc core neuronal responses to the cues (Meffre et al., 2019). This suggests the existence of a orexin neurons $=>$ pPVT $=>$ NAc core circuit that conveys energy-balance information to drive cue responses in this sucrose-seeking task (Meffre et al., 2019), highlighting again the involvement of these projections in processing homeostatic inputs.

Despite some contradictions, probably due to the precise neuronal targeting, all these papers demonstrate the crucial role of $\mathrm{PVT}=>$ NAc in integrating and processing reward-relevant inputs to drive appropriate goal-directed behaviors. Importantly, some discrepancies across laboratories in the directionality of the effect of PVT $=>$ NAc stimulation or inhibition may also be explained by the internal states (such as arousal and metabolic state) or past experience information integrated by the PVT.

\section{DRUG EXPERIENCE AND ADDICTION}

Interestingly, these reward processing mechanisms can also be hijacked by drugs of abuse. The PVT has been known to be involved in several aspects of drug-induced behaviors, including the locomotor response to psychostimulants (Young and Deutch, 1998; Clark et al., 2017), cue-reward association (Brown et al., 1992), expression of drug-induced place preference (Browning et al., 2014), withdrawal (Smith et al., 2020), and reinstatement of drug-seeking (James et al., 2010). The roles of thalamus in addiction have been reviewed elsewhere (Huang et al., 2018).

Several studies shed light on changes occurring specifically at thalamo $=>$ NAc synapses after drug of abuse experience (Table 1). Cocaine experience was shown to enhance AMPAR and NMDA receptor (NMDAR) functions at the synapses between the MTN and D1-MSNs in the NAc core. The altered NMDAR properties most likely resulted from the incorporation of GluN2C/D-containing NMDARs. The cocaine exposure also generated silent synapses between the MTN and D2-MSNs (Joffe and Grueter, 2016). Similarly, another study showed that one day of cocaine self-administration increased the level of AMPAR-silent PVT $=>$ NAc shell synapses, likely by the insertion of GluN2B-containing NMDARs. In addition, the presynaptic release probability was increased. After withdrawal, silent synapses returned to basal levels, probably through the insertion of non-calcium-permeable AMPARs. In contrast, the basal presynaptic release probability of these synapses between the PVT and NAc shell was persistently increased after cocaine exposure (Neumann et al., 2016). Lastly, a third study showed that escalating morphine regimen increased $\mathrm{AMPAR} / \mathrm{NMDAR}$ ratio at $\mathrm{PVT}=>\mathrm{NAc}$ synapses in D2- but not D1-MSNs, probably by the insertion of calcium-permeable AMPARs (Zhu et al., 2016). Different drugs of abuse thus alter these thalamo $=>$ NAc synapses at short and long term, through both pre- and postsynaptic mechanisms.

Several groups have also begun to decipher the functional and behavioral importance of PVT $=>$ NAc in various aspects of addiction (Table 1). Disruption of synaptic transmission between the PVT and the NAc demonstrated that PVT $=>$ NAc was necessary for cocaine self-administration (Neumann et al., 2016). In addition, inhibition of PVT $=>$ NAc disrupted the expression of a morphine conditioned place preference (CPP) (during and one day after the inhibition), and prevented morphineprimed relapse (Keyes et al., 2020). Moreover, inhibition of the PVT caused a disinhibition of NAc $=>$ lateral hypothalamus and the blockade of the CPP retrieval, highlighting a $\mathrm{PVT}=>\mathrm{NAc}=>$ lateral hypothalamus pathway important for the retrieval and maintenance of opiate-associated memories (Keyes et al., 2020).

PVT $=>$ NAc also mediates the aversive symptoms of opiate withdrawal, as photoinhibition of PVT $=>$ NAc medial shell reduced the aversive effects of both naloxone-induced and spontaneous opiate withdrawal (Zhu et al., 2016). This effect was not specific to opiate withdrawal since these projections were also necessary for mild footshock and injections of $\mathrm{LiCl}$ to evoke behavioral aversion (Zhu et al., 2016). With regards to relapse, inhibition of the MTN (including the PVT) and intralaminar thalamic nuclei during the reinstatement of cocaine seeking reduced both cue-induced and drugprimed reinstatement, but did not affect the reinstatement of 
sucrose-seeking (Wunsch et al., 2017). Interestingly, specifically decreasing the activity of the anterior MTN $=>$ NAc neurons increased cue-induced but reduced drug-primed reinstatement of cocaine seeking, suggesting different mechanisms by which MTN $=>$ NAc neurons modulate these two types of relapse (Wunsch et al., 2017).

Finally, two studies also linked drug-seeking behavior to the hunger state of the animal, by showing that chronic foodrestriction increased heroin-seeking behavior after withdrawal from self-administration. This phenomenon was modulated by $\mathrm{PVT}=>$ NAc shell neurons, as their enhanced activity attenuated this food restriction-induced heroin seeking (Chisholm et al., 2020, 2021), demonstrating an overlap between PVT $=>$ NAc circuits driving food- and drug-seeking behaviors.

All these studies highlight a key role of PVT $=>$ NAc in various aspects of drug-induced behaviors, from selfadministration and conditioned drug seeking to the negative states induced by withdrawal, and relapse.

\section{DISCUSSION AND CONCLUSION}

In this mini-review, we have highlighted the latest research advancements toward understanding the roles of thalamo $=>$ NAc projections (mainly $\mathrm{PVT}=>\mathrm{NAc}$ ) in various aspects of motivated behaviors, including reinforcement, reward-seeking and addiction. These PVT $=>$ NAc projections, depending on their activity pattern, seem to be able to drive both aversive and reinforcing behaviors. A growing amount of evidence also showed a specific role of these afferents in various homeostatic behaviors, including arousal and feeding, as well as in cue-reward association. Moreover, drug exposure has been shown to induce both short- and long-term modifications at thalamo $=>$ NAc synapses, and these projections have been

\section{REFERENCES}

Adamantidis, A., and de Lecea, L. (2009). The hypocretins as sensors for metabolism and arousal. J. Physiol. 587, 33-40. doi: 10.1113/jphysiol.2008. 164400

Ambroggi, F., Ghazizadeh, A., Nicola, S. M., and Fields, H. L. (2011). Roles of nucleus accumbens core and shell in incentive-cue responding and behavioral inhibition. J. Neurosci. 31, 6820-6830. doi: 10.1523/JNEUROSCI.6491-10.2011

Baimel, C., Bartlett, S. E., Chiou, L. C., Lawrence, A. J., Muschamp, J. W., Patkar, O., et al. (2015). Orexin/hypocretin role in reward: implications for opioid and other addictions. Br. J. Pharmacol. 172, 334-348. doi: 10.1111/bph.12639

Belin, D., and Everitt, B. J. (2008). Cocaine seeking habits depend upon dopaminedependent serial connectivity linking the ventral with the dorsal striatum. Neuron 57, 432-441. doi: 10.1016/j.neuron.2007.12.019

Britt, J. P., Benaliouad, F., McDevitt, R. A., Stuber, G. D., Wise, R. A., and Bonci, A. (2012). Synaptic and behavioral profile of multiple glutamatergic inputs to the nucleus accumbens. Neuron 76, 790-803. doi: 10.1016/j.neuron.2012.09.040

Brown, E. E., Robertson, G. S., and Fibiger, H. C. (1992). Evidence for conditional neuronal activation following exposure to a cocaine-paired environment: role of forebrain limbic structures. J. Neurosci. 12, 4112-4121. doi: 10.1523/jneurosci. 12-10-04112.1992

Browning, J. R., Jansen, H. T., and Sorg, B. A. (2014). Inactivation of the paraventricular thalamus abolishes the expression of cocaine conditioned place preference in rats. Drug Alcohol Depend. 134, 387-390. doi: 10.1016/j. drugalcdep.2013.09.021 demonstrated to play key roles in drug-seeking, withdrawal and relapse. Despite the increasing quantity of papers investigating the functions of these thalamo $=>$ NAc projections, more studies will be necessary to fully understand their precise roles in motivated behaviors and addiction. Moreover, the cellular diversity of thalamo $=>$ NAc neurons, the inputs influencing their activity and their precise encoding of reward-relevant information still remain to be fully deciphered. Finally, future studies with good spatial resolution and precise distinctions between the aPVT and pPVT as well as between the different regions of the NAc are likely to contribute to reconciling some contradictory findings of the recent literature.

\section{AUTHOR CONTRIBUTIONS}

$\mathrm{AD}$ and $\mathrm{AK}$ wrote the manuscript and edited and contributed to the final version of the manuscript. AK supervised all aspects of the work. Both authors contributed to the article and approved the submitted version.

\section{FUNDING}

AD was supported by a fellowship of the F.R.S.-FNRS (Belgium). AK is a Research Director of the F.R.S.-FNRS (Belgium). F.R.S.FNRS, Fondation Simone et Pierre Clerdent, ULB, Fondation ULB, supported AK.

\section{ACKNOWLEDGMENTS}

We thank Christophe Varin and Michele Zoli for helpful comments and corrections on the manuscript.

Campus, P., Covelo, I. R., Kim, Y., Parsegian, A., Kuhn, B. N., Lopez, S. A., et al. (2019). The paraventricular thalamus is a critical mediator of top-down control of cue-motivated behavior in rats. Elife 8:e49041. doi: 10.7554/eLife.49041

Carelli, R. M. (2002). The nucleus accumbens and reward: neurophysiological investigations in behaving animals. Behav. Cogn. Neurosci. Rev. 1, 281-296. doi: $10.1177 / 1534582302238338$

Cheng, J., Wang, J., Ma, X., Ullah, R., Shen, Y., and Zhou, Y. D. (2018). Anterior paraventricular thalamus to nucleus accumbens projection is involved in feeding behavior in a novel environment. Front. Mol. Neurosci. 11:202. doi: 10.3389/fnmol.2018.00202

Chisholm, A., Iannuzzi, J., Rizzo, D., Gonzalez, N., Fortin, E., Bumbu, A., et al. (2020). The role of the paraventricular nucleus of the thalamus in the augmentation of heroin seeking induced by chronic food restriction. Addict. Biol. 25:e12708. doi: 10.1111/adb.12708

Chisholm, A., Rizzo, D., Fortin, É, Moman, V., Quteishat, N., Romano, A., et al. (2021). Assessing the role of corticothalamic and thalamo- accumbens projections in the augmentation of heroin seeking in chronically foodrestricted rats. J. Neurosci. 41, 354-365. doi: 10.1523/JNEUROSCI.2103-20. 2020

Choi, D. L., Davis, J. F., Fitzgerald, M. E., and Benoit, S. C. (2010). The role of orexin-A in food motivation, reward-based feeding behavior and foodinduced neuronal activation in rats. Neuroscience 167, 11-20. doi: 10.1016/j. neuroscience.2010.02.002

Choi, D. L., Davis, J. F., Magrisso, I. J., Fitzgerald, M. E., Lipton, J. W., and Benoit, S. C. (2012). Orexin signaling in the paraventricular thalamic nucleus 
modulates mesolimbic dopamine and hedonic feeding in the rat. Neuroscience 210, 243-248. doi: 10.1016/j.neuroscience.2012.02.036

Choi, E. A., Jean-Richard-Dit-Bressel, P., Clifford, C. W. G., and McNally, G. P. (2019). Paraventricular thalamus controls behavior during motivational conflict. J. Neurosci. 39, 4945-4958. doi: 10.1523/JNEUROSCI.2480-18.2019

Choi, E. A., and McNally, G. P. (2017). Paraventricular thalamus balances danger and reward. J. Neurosci. 37, 3018-3029. doi: 10.1523/JNEUROSCI.3320-16. 2017

Christoffel, D. J., Walsh, J. J., Heifets, B. D., Hoerbelt, P., Neuner, S., Sun, G., et al. (2021). Input-specific modulation of murine nucleus accumbens differentially regulates hedonic feeding. Nat. Commun. 12:2135. doi: 10.1038/s41467-02122430-7

Clark, A. M., Leroy, F., Martyniuk, K. M., Feng, W., McManus, E., Bailey, M. R., et al. (2017). Dopamine D2 receptors in the paraventricular thalamus attenuate cocaine locomotor sensitization. eNeuro 4:ENEURO.0227-17.2017. doi: 10 . 1523/ENEURO.0227-17.2017

Cover, K. K., Gyawali, U., Kerkhoff, W. G., Patton, M. H., Mu, C., White, M. G., et al. (2019). Activation of the rostral intralaminar thalamus drives reinforcement through striatal dopamine release. Cell Rep. 26, 1389-1398. doi: 10.1016/j.celrep.2019.01.044

De Jong, J. W., Afjei, S. A., Dorocic, I. P., Peck, J. R., Liu, C., Kim, C. K., et al. (2019). A neural circuit mechanism for encoding aversive stimuli in the mesolimbic dopamine system. Neuron 101, 133-151. doi: 10.1016/j.neuron.2018.11.005

Do-Monte, F. H., Minier-Toribio, A., Quiñones-Laracuente, K., Medina-Colón, E. M., and Quirk, G. J. (2017). Thalamic regulation of sucrose seeking during unexpected reward omission. Neuron 94, 388-400. doi: 10.1016/j.neuron.2017. 03.036

Doig, N. M., Moss, J., and Bolam, J. P. (2010). Cortical and thalamic innervation of direct and indirect pathway medium-sized spiny neurons in mouse striatum. J. Neurosci. 30, 14610-14618. doi: 10.1523/JNEUROSCI.1623-10.2010

Dong, X., Li, S., and Kirouac, G. J. (2017). Collateralization of projections from the paraventricular nucleus of the thalamus to the nucleus accumbens, bed nucleus of the stria terminalis, and central nucleus of the amygdala. Brain Struct. Funct. 222, 3927-3943. doi: 10.1007/s00429-017-1445-8

Engelke, D. S., Zhang, X. O., O’Malley, J. J., Fernandez-Leon, J. A., Li, S., Kirouac, G. J., et al. (2021). A hypothalamic-thalamostriatal circuit that controls approach-avoidance conflict in rats. Nat. Commun. 12:2517. doi: 10.1038/ s41467-021-22730-y

Everitt, B. J., and Robbins, T. W. (2016). Drug addiction: updating actions to habits to compulsions ten years on. Annu. Rev. Psychol. 67, 23-50. doi: 10.1146/ annurev-psych-122414-033457

Gao, C., Leng, Y., Ma, J., Rooke, V., Rodriguez-gonzalez, S., Ramakrishnan, C., et al. (2020). Two genetically, anatomically and functionally distinct cell types segregate across anteroposterior axis of paraventricular thalamus. Nat. Neurosci. 23, 217-228. doi: 10.1038/s41593-019-0572-3

Goodman, A. (2008). Neurobiology of addiction. An integrative review. Biochem. Pharmacol. 75, 266-322. doi: 10.1016/j.bcp.2007.07.030

Groenewegen, H. J., and Witter, M. P. (2004). "Thalamus," in The Rat Nervous System, ed. G. Paxinos (San Diego, CA: Academic Press), 408-441.

Haghparast, A., Fatahi, Z., Arezoomandan, R., Karimi, S., Taslimi, Z., and Zarrabian, S. (2017). Functional roles of orexin/hypocretin receptors in reward circuit. Prog. Brain Res. 235, 139-154. doi: 10.1016/bs.pbr.2017.08.005

Haight, J. L., Campus, P., Maria-rios, C. E., Johnson, A. M., Klumpner, M. S., Kuhn, B. N., et al. (2020). The lateral hypothalamus and orexinergic transmission in the paraventricular thalamus promote the attribution of incentive salience to reward-associated cues. Psychopharmacology (Berl) 237, 3741-3758. doi: 10. 1007/s00213-020-05651-4

Haight, J. L., Fraser, K. M., Akil, H., Flagel, S. B., Arbor, A., Arbor, A., et al. (2015). Lesions of the paraventricular nucleus of the thalamus differentially affect signand goal-tracking conditioned responses. Eur. J. Neurosci. 42, 2478-2488. doi: 10.1111/ejn.13031

Haight, J. L., Fuller, Z. L., Fraser, K. M., Flagel, S. B., Arbor, A., Arbor, A., et al. (2017). A food-predictive cue attributed with incentive salience engages subcortical afferents and efferents of the paraventricular nucleus of the thalamus. Neuroscience 340, 135-152. doi: 10.1016/j.neuroscience.2016.10.043

Hsu, D. T., Kirouac, G. J., Zubieta, J., and Bhatnagar, S. (2014). Contributions of the paraventricular thalamic nucleus in the regulation of stress, motivation, and mood. Front. Behav. Neurosci. 8:73. doi: 10.3389/fnbeh.2014.00073
Huang, A. S., Mitchell, J. A., Haber, S. N., Alia-klein, N., Goldstein, R. Z., and Goldstein, R. Z. (2018). The thalamus in drug addiction: from rodents to humans. Philos. Trans. R. Soc. Lond. B Biol. Sci. 373:20170028. doi: 10.1098/ rstb. 2017.0028

Igelstrom, K. M., Herbison, A. E., and Hyland, B. I. (2010). Enhanced c-Fos expression in superior colliculus, paraventricular thalamus and septum during learning of cue-reward association. Neuroscience 168, 706-714. doi: 10.1016/j. neuroscience.2010.04.018

Ikemoto, S., and Panksepp, J. (1999). The role of nucleus accumbens dopamine in motivated behavior: a unifying interpretation with special reference to reward-seeking. Brain Res. Rev. 31, 6-41. doi: 10.1016/s0165-0173(99)00023-5

James, M. H., Charnley, J. L., Jones, E., Levi, E. M., Yeoh, J. W., Flynn, J. R., et al. (2010). Cocaine- and amphetamine-regulated transcript (CART) signaling within the paraventricular thalamus modulates cocaine-seeking behaviour. PLoS One 5:e12980. doi: 10.1371/journal.pone.0012980

Joffe, M. E., and Grueter, B. A. (2016). Cocaine experience enhances thalamoaccumbens N-methyl-D-aspartate receptor function. Biol. Psychiatry 80, 671681. doi: $10.1016 /$ j.biopsych.2016.04.002

Johansson, Y., and Silberberg, G. (2020). The functional organization of cortical and thalamic inputs onto five types of striatal neurons is determined by source and target cell identities. Cell Rep. 30, 1178-1194. doi: 10.1016/j.celrep.2019.12. 095

Johnson, K. A., Mateo, Y., and Lovinger, D. M. (2017). Metabotropic glutamate receptor 2 inhibits thalamically-driven glutamate and dopamine release in the dorsal striatum. Neuropharmacology 117, 114-123. doi: 10.1016/j.neuropharm. 2017.01.038

Kelley, A. E., Baldo, B. A., and Pratt, W. E. (2005). A proposed hypothalamicthalamic-striatal axis for the integration of energy balance, arousal, and food reward. J. Comp. Neurol. 493, 72-85. doi: 10.1002/cne.20769

Keyes, P. C., Adams, E. L., Chen, Z., Bi, L., Nachtrab, G., Wang, V. J., et al. (2020). Orchestrating opiate-associated memories in thalamic circuits. Neuron 107, 1113-1123. doi: 10.1016/j.neuron.2020.06.028

Kirouac, G. J. (2015). Placing the paraventricular nucleus of the thalamus within the brain circuits that control behavior. Neurosci. Biobehav. Rev. 56, 315-329. doi: 10.1016/j.neubiorev.2015.08.005

Kirouac, G. J. (2021). The paraventricular nucleus of the thalamus as an integrating and relay node in the brain anxiety network. Front. Behav. Neurosci. 15:627633. doi: 10.3389/fnbeh.2021.627633

Kirouac, G. J., Parsons, M. P., and Li, S. (2005). Orexin (hypocretin) innervation of the paraventricular nucleus of the thalamus. Brain Res. 1059, 179-188. doi: 10.1016/j.brainres.2005.08.035

Klawonn, A. M., and Malenka, R. C. (2018). Nucleus accumbens modulation in reward and aversion. Cold Spring Harb. Symp. Quant. Biol. 83, 119-129. doi: 10.1101/sqb.2018.83.037457.Nucleus

Klug, J. R., Engelhardt, M. D., Cadman, C. N., Li, H., Smith, J. B., Ayala, S., et al. (2018). Differential inputs to striatal cholinergic and parvalbumin interneurons imply functional distinctions. Elife 7:e35657. doi: 10.7554/eLife.35657

Kosillo, P., Zhang, Y. F., Threlfell, S., and Cragg, S. J. (2016). Cortical control of striatal dopamine transmission via striatal cholinergic interneurons. Cereb. Cortex 26, 4160-4169. doi: 10.1093/cercor/bhw252

Labouèbe, G., Boutrel, B., Tarussio, D., and Thorens, B. (2016). Glucose-responsive neurons of the paraventricular thalamus control sucrose-seeking behavior. Nat. Neurosci. 19, 999-1002. doi: 10.1038/nn.4331

Lafferty, C. K., Yang, A. K., Mendoza, J. A., and Britt, J. P. (2020). Nucleus accumbens cell type- and input-specific suppression of unproductive reward seeking. Cell Rep. 30, 3729-3742. doi: 10.1016/j.celrep.2020. 02.095

Lee, J. S., Lee, E. Y., and Lee, H. S. (2015). Hypothalamic, feeding/arousal-related peptidergic projections to the paraventricular thalamic nucleus in the rat. Brain Res. 1598, 97-113. doi: 10.1016/j.brainres.2014.12.029

Leshner, A. I. (1997). Addiction is a brain disease, and it matters. Science 278, 45-47. doi: 10.1126/science.278.5335.45

Li, S., and Kirouac, G. J. (2012). Sources of inputs to the anterior and posterior aspects of the paraventricular nucleus of the thalamus. Brain Struct. Funct. 217, 257-273. doi: 10.1007/s00429-011-0360-7

Mahler, S. V., Moorman, D. E., Smith, R. J., James, M. H., and Aston-Jones, G. (2014). Motivational activation: a unifying hypothesis of orexin/hypocretin function. Nat. Neurosci. 17, 1298-1303. doi: 10.1038/nn.3810 
McGinty, J. F., and Otis, J. M. (2020). Heterogeneity in the paraventricular thalamus: the traffic light of motivated behaviors. Front. Behav. Neurosci. 14:590528. doi: 10.3389/fnbeh.2020.590528

Meffre, J., Sicre, M., Diarra, M., Marchessaux, F., Paleressompoulle, D., and Ambroggi, F. (2019). Orexin in the posterior paraventricular thalamus mediates hunger-related signals in the nucleus accumbens core. Curr. Biol. 29, 32983306. doi: 10.1016/j.cub.2019.07.069

Mogenson, G. J., Jones, D. L., and Yiu Yim, C. (1980). From motivation to action: functional interface between the limbic system and the motor system. Prog. Neurobiol. 14, 69-97. doi: 10.1016/0301-0082(80)90018-0

Munkhzaya, U., Chinzorig, C., Matsumoto, J., Nishimaru, H., Ono, T., and Nishijo, H. (2020). Rat paraventricular neurons encode predictive and incentive information of reward cues. Front. Behav. Neurosci. 14:565002. doi: 10.3389/ fnbeh.2020.565002

Nestler, E. J. (2013). Cellular basis of memory for addiction. Dialogues Clin. Neurosci. 15, 431-443. doi: 10.31887/DCNS.2013.15.4/enestler

Neumann, P. A., Wang, Y., Yan, Y., Wang, Y., Ishikawa, M., Cui, R., et al. (2016). Cocaine-induced synaptic alterations in thalamus to nucleus accumbens projection. Neuropsychopharmacology 41, 2399-2410. doi: 10.1038/npp. 2016.52

Otis, J. M., Namboodiri, V. M. K., Matan, A. M., Voets, E. S., Mohorn, E. P., Kosyk, O., et al. (2017). Prefrontal cortex output circuits guide reward seeking through divergent cue encoding. Nature 543, 103-107. doi: 10.1038/nature21376

Otis, J. M., Zhu, M. H., Namboodiri, V. M. K., Cook, C. A., Kosyk, O., Matan, A. M., et al. (2019). Paraventricular thalamus projection neurons integrate cortical and hypothalamic signals for cue-reward processing. Neuron 103, 423-431. doi: 10.1016/j.neuron.2019.05.018

Parsons, M. P., Li, S., and Kirouac, G. J. (2007). Functional and anatomical connection between the paraventricular nucleus of the thalamus and dopamine fibers of the nucleus accumbens. J. Comp. Neurol. 500, 1050-1063. doi: 10.1002/ cne. 21224

Penzo, M. A., and Gao, C. (2021). The paraventricular nucleus of the thalamus: an integrative node underlying homeostatic behavior. Trends Neurosci. 44, 538-549. doi: 10.1016/j.tins.2021.03.001

Perez, S. M., and Lodge, D. J. (2018). Convergent inputs from the hippocampus and thalamus to the nucleus accumbens regulate dopamine neuron activity. J. Neurosci. 38, 10607-10618. doi: 10.1523/JNEUROSCI.2629-16.2018

Phillipson, O. T., and Griffiths, A. C. (1985). The topographic order of inputs to nucleus accumbens in the rat. Neuroscience 16, 275-296. doi: 10.1016/0306$4522(85) 90002-8$

Pinto, A., Jankowski, M., and Sesack, S. R. (2003). Projections from the paraventricular nucleus of the thalamus to the rat prefrontal cortex and nucleus accumbens shell: ultrastructural characteristics and spatial relationships with dopamine afferents. J. Comp. Neurol. 459, 142-155. doi: 10.1002/cne.10596

Qi, J., Zhang, S., Wang, H.-L., Barker, D. J., Miranda-Barrientos, J., and Morales, M. (2016). VTA glutamatergic inputs to nucleus accumbens drive aversion by acting on GABAergic interneurons. Nat. Neurosci. 19, 725-733. doi: 10.1038/ nn. 4281

Ren, S., Wang, Y., Yue, F., Cheng, X., Dang, R., Qiao, Q., et al. (2018). The paraventricular thalamus is a critical thalamic area for wakefulness. Science 362, 429-434. doi: 10.1126/science.aat 2512

Reynolds, S. M., and Berridge, K. C. (2002). Positive and negative motivation in nucleus accumbens shell: bivalent rostrocaudal gradients for GABA-elicited eating, taste "liking"/"disliking" reactions, place preference/avoidance, and fear. J. Neurosci. 22, 7308-7320. doi: 10.1523/jneurosci.22-16-07308.2002

Sakurai, T. (2014). The role of orexin in motivated behaviours. Nat. Rev. Neurosci. 15, 719-731. doi: 10.1038/nrn3837

Scofield, M. D., Heinsbroek, J. A., Gipson, C. D., Kupchik, Y. M., Spencer, S., Smith, A. C. W., et al. (2016). The nucleus accumbens: mechanisms of addiction across drug classes reflect the importance of glutamate homeostasis. Pharmacol. Rev. 68, 816-871. doi: 10.1124/pr.116.012484

Smith, R. J., Anderson, R. I., Haun, H. L., Mulholland, P. J., Iii, W. C. G., Lopez, M. F., et al. (2020). Dynamic c-Fos changes in mouse brain during acute and protracted withdrawal from chronic intermittent ethanol exposure and relapse drinking. Addict. Biol. 25:e12804. doi: 10.1111/adb.12804

Smith, Y., Raju, D. V., Pare, J. F., and Sidibe, M. (2004). The thalamostriatal system: a highly specific network of the basal ganglia circuitry. Trends Neurosci. 27, 520-527. doi: 10.1016/j.tins.2004.07.004
Stratford, T. R., and Kelley, A. E. (1999). Evidence of a functional relationship between the nucleus accumbens shell and lateral hypothalamus subserving the control of feeding behavior. J. Neurosci. 19, 11040-11048. doi: 10.1523/ JNEUROSCI.19-24-11040.1999

Stuber, G. D., Sparta, D. R., Stamatakis, A. M., Van Leeuwen, W. A., Hardjoprajitno, J. E., Cho, S., et al. (2011). Amygdala to nucleus accumbens excitatory transmission facilitates reward seeking. Nature 475, 377-380. doi: 10.1038/ nature10194

Su, H. S., and Bentivoglio, M. (1990). Thalamic midline cell populations projecting to the nucleus accumbens, amygdala, and hippocampus in the rat. J. Comp. Neurol. 297, 582-593. doi: 10.1002/cne.902970410

Threlfell, S., Lalic, T., Platt, N. J., Jennings, K. A., Deisseroth, K., and Cragg, S. J. (2012). Striatal dopamine release is triggered by synchronized activity in cholinergic interneurons. Neuron 75, 58-64. doi: 10.1016/j.neuron.2012.04.038

Vertes, R. P., and Hoover, W. B. (2008). Projections of the paraventricular and paratenial nuclei of the dorsal midline thalamus in the rat. J. Comp. Neurol. 508, 212-237. doi: 10.1002/cne.21679

Vertes, R. P., Linley, S. B., and Hoover, W. B. (2015). Limbic circuitry of the midline thalamus. Neurosci. Biobehav. Rev. 54, 89-107. doi: 10.1016/j.neubiorev.2015. 01.014

Wall, N. R., De La Parra, M., Callaway, E. M., and Kreitzer, A. C. (2013). Differential innervation of direct- and indirect-pathway striatal projection neurons. Neuron 79, 347-360. doi: 10.1016/j.neuron.2013.05.014

Wunsch, A. M., Yager, L. M., Donckels, E. A., Le, C. T., Neumaier, J. F., and Ferguson, S. M. (2017). Chemogenetic inhibition reveals midline thalamic nuclei and thalamo-accumbens projections mediate cocaine-seeking in rats. Eur. J. Neurosci. 46, 1850-1862. doi: 10.1111/ejn.13631

Yager, L. M., Garcia, A. F., Wunsch, A. M., Ferguson, S. M., and Sciences, B. (2015). The ins and outs of the striatum: role in drug addiction. Neuroscience 301, 529-541. doi: 10.1016/j.neuroscience.2015.06.033

Yang, H., De Jong, J. W., Tak, Y., Peck, J., Bateup, H., and Lammel, S. (2018). Nucleus accumens subnuclei regulate motivated behavior via direct inhibition and disinhibition of VTA dopamine subpopulations. Neuron 97, 434-449. doi: 10.1016/j.neuron.2017.12.022

Yoo, J. H., Zell, V., Gutierrez-Reed, N., Wu, J., Ressler, R., Shenasa, M. A., et al. (2016). Ventral tegmental area glutamate neurons co-release GABA and promote positive reinforcement. Nat. Commun. 7:13697. doi: 10.1038/ ncomms 13697

Young, C. D., and Deutch, A. Y. (1998). The effects of thalamic paraventricular nucleus lesions on cocaine-induced locomotor activity and sensitization. Pharmacol. Biochem. Behav. 60, 753-758. doi: 10.1016/S0091-3057(98)00051-3

Yuan, X. L., Dou, X. Y., and Sun, X. Y. (2019). Topography of reward and aversion encoding in the mesolimbic dopaminergic system. J. Neurosci. 39, 6472-6481. doi: 10.1523/JNEUROSCI.0271-19.2019

Zell, V., Steinkellner, T., Hollon, N. G., Warlow, S. M., Souter, E., Faget, L., et al. (2020). VTA glutamate neuron activity drives positive reinforcement absent dopamine co-release. Neuron 107, 864-873. doi: 10.1016/j.neuron.2020.06.011

Zhou, K., Zhu, L., Hou, G., Chen, X., Chen, B., Yang, C., et al. (2021). The contribution of thalamic nuclei in salience processing. Front. Behav. Neurosci. 15:634618. doi: 10.3389/fnbeh.2021.634618

Zhu, Y., Nachtrab, G., Keyes, P. C., Allen, W. E., Luo, L., and Chen, X. (2018). Dynamic salience processing in paraventricular thalamus gates associative learning. Science 362, 423-429. doi: 10.1126/science.aat 0481

Zhu, Y., Wienecke, C. F. R., Nachtrab, G., and Chen, X. (2016). A thalamic input to the nucleus accumbens mediates opiate dependence. Nature 530, 219-222. doi: $10.1038 /$ nature 16954

Conflict of Interest: The authors declare that the research was conducted in the absence of any commercial or financial relationships that could be construed as a potential conflict of interest.

Copyright ( 2021 De Groote and de Kerchove d'Exaerde. This is an open-access article distributed under the terms of the Creative Commons Attribution License (CC BY). The use, distribution or reproduction in other forums is permitted, provided the original author(s) and the copyright owner(s) are credited and that the original publication in this journal is cited, in accordance with accepted academic practice. No use, distribution or reproduction is permitted which does not comply with these terms. 